\title{
Correction to: Incidence and characteristics of metastatic intracranial lesions in stage III and IV melanoma: a single institute retrospective analysis
}

Mani Ratnesh S. Sandhu ${ }^{1}$ (1) Veronica L. Chiang ${ }^{2} \cdot$ Thuy Tran $^{3}$. James B. Yu ${ }^{4} \cdot$ Sarah A. Weiss ${ }^{3} \cdot$ Sarah B. Goldberg ${ }^{3}$. Mariam S. Aboian ${ }^{5} \cdot$ Harriet M. Kluger ${ }^{3} \cdot$ Amit Mahajan $^{5}$

Published online: 17 August 2021

(c) The Author(s), under exclusive licence to Springer Science+Business Media, LLC, part of Springer Nature 2021

Correction to: Journal of Neuro-Oncology

https://doi.org/10.1007/s11060-021-03813-8

In this article the names of the 5th, 6th and 7th authors were first published without the middle name initials. The original article has been corrected.

Publisher's Note Springer Nature remains neutral with regard to jurisdictional claims in published maps and institutional affiliations.

The original article can be found online at https://doi.org/10.1007/ s11060-021-03813-8.

Amit Mahajan amit.mahajan@yale.edu

1 Laboratory Medicine, Yale School of Medicine, New Haven, CT, USA

2 Neurosurgery, Yale School of Medicine, New Haven, CT, USA

3 Internal Medicine (Medical Oncology), Yale School of Medicine, New Haven, CT, USA

4 Therapeutic Radiology, Yale School of Medicine, New Haven, CT, USA

5 Radiology and Biomedical Imaging, Yale School of Medicine, New Haven, CT, USA 